\title{
Clearing the air: A study of cannabis-related presentations to urban Alberta emergency departments following legalization
}

\author{
Matthew E. M. Yeung*; Colin G. Weaver, BSc ${ }^{\dagger}$; Kevin Janz, MD; Rebecca Haines-Saah, PhD ${ }^{\dagger}$; \\ Eddy Lang, MD*
}

\begin{abstract}
CLINICIAN'S CAPSULE
What is known about the topic?

Legalization of non-medical cannabis may impact the volume of cannabis-related emergency department (ED) visits and may alter historical co-diagnoses patterns.

What did this study ask?

What was the impact of national non-medical cannabis legalization in urban Alberta on cannabis-related ED visit volume and co-diagnoses patterns?

What did this study find?

Urban cannabis-related visits increased $45 \%$, though for individual EDs, average increase was 3.1 visits per ED per month.

Why does this study matter to clinicians?

Clinicians in other provinces and countries considering non-medical cannabis legalization should not expect alarming changes in cannabis-related ED visit volume.
\end{abstract}

\section{ABSTRACT}

Objectives: Non-medical cannabis recently became legal for adults in Canada. Legalization provides opportunity to investigate the public health effects of national cannabis legalization on presentations to emergency departments (EDs). Our study aimed to explore association between cannabis-related ED presentations, poison control and telemedicine calls, and cannabis legalization.

Methods: Data were collected from the National Ambulatory Care Reporting System from October 1, 2013, to July 31, 2019, for 14 urban Alberta EDs, from Alberta poison control, and from HealthLink, a public telehealth service covering all of Alberta. Visitation data were obtained to compare pre- and post-legalization periods. An interrupted time-series analysis accounting for existing trends was completed, in addition to the incidence rate ratio (IRR) and relative risk calculation (to evaluate changes in co-diagnoses).

Results: Although only 3 of every 1,000 ED visits within the time period were attributed to cannabis, the number of cannabis-related ED presentations increased post-legalization by 3.1 (range -11.5 to 12.6 ) visits per ED per month (IRR 1.45, 95\% confidence interval [Cl]; 1.39, 1.51; absolute level change: 43.5 visits per month, $95 \% \mathrm{Cl}$; 26.5, 60.4). Cannabis-related calls to poison control also increased (IRR 1.87, $95 \% \mathrm{Cl} ; 1.55$, 2.37; absolute level change: 4.0 calls per month, $95 \% \mathrm{Cl} ; 0.1$, 7.9). Lastly, we observed increases in cannabis-related hyperemesis, unintentional ingestion, and individuals leaving the ED pre-treatment. We also observed a decrease in co-ingestant use.

Conclusion: Overall, Canadian cannabis legalization was associated with small increases in urban Alberta cannabis-related ED visits and calls to a poison control centre.

\section{RÉSUMÉ}

Objectif: Les adultes ont maintenant le droit, depuis peu, de faire un usage non médical du cannabis au Canada. Le changement de politique donne ainsi l'occasion d'étudier, du point de vue de la santé publique, les effets de la légalisation du cannabis au pays sur les consultations aux services des urgences (SU). L'étude visait à examiner l'association entre les consultations au SU liées à l'usage du cannabis, les appels au centre antipoison et en télémédecine, et la légalisation du cannabis. Méthode: Les données recueillies provenaient du National Ambulatory Care Reporting System, couvrant la période du $1^{\mathrm{er}}$ octobre 2013 au 31 juillet 2019 et concernant 14 SU situés en milieu urbain, en Alberta; du centre antipoison de I'Alberta ainsi que de HealthLink, un service public pan-albertain de télémédecine. La collecte de données visait à comparer le nombre de consultations avant et après la légalisation de la drogue. L'équipe a procédé à une analyse de séries temporelles

From the ${ }^{*}$ Department of Emergency Medicine, University of Calgary, Calgary, AB; ${ }^{\dagger}$ Department of Community Health Sciences, University of Calgary, Calgary, $A B$; and ${ }^{\ddagger}$ Department of Family Medicine, University of Calgary, Calgary, AB.

Correspondence to: Matthew Yeung, Holy Cross Ambulatory Care Centre, 5A105, 7007 14th St. SW, Calgary, AB T2V 1P9; Email: Matthew.yeung1 @ ucalgary.ca. 
interrompues pour tenir compte des tendances existantes à l'époque, en plus de calculer les ratios des taux d'incidence (RTI) et les risques relatifs (RR) (pour l'évaluation des changements de diagnostics mixtes).

Résultats: Bien que 3 consultations sur 1000 seulement au SU, durant la période à l'étude, soient attribuables au cannabis, le nombre de consultations au SU liées à l'usage du cannabis a augmenté de 3,1 par SU, par mois (plage : $-11,5$ à 12,6), après la légalisation ( $R T I$ : 1,45; IC à $95 \%$ : 1,39-1,51; écart en valeur absolue : 43,5 consultations par mois; IC à $95 \%$ : 26,5$60,4)$. Une hausse du nombre d'appels liés à l'usage du cannabis a également été enregistrée au centre antipoison (RTI : 1,87; IC à 95\% : 1,55-2,37; écart en valeur absolue : 4,0 appels par mois; IC à 95\% : 0,1-7,9). Enfin, une augmentation du nombre de cas d'hyperémèse liée à l'usage du cannabis et d'ingestion involontaire de la drogue ainsi que du nombre de personnes parties sans avoir été examinées a été observée; toutefois, I'usage concomitant de substances psychoactives, lui, a diminué.

Conclusion: Dans l'ensemble, la légalisation du cannabis au Canada a été associée à une faible augmentation du nombre de consultations dans les SU situés en milieu urbain, en Alberta, ainsi que du nombre d'appels au centre antipoison, liés à l'usage du cannabis.

Keywords: Cannabis, legalization, public health

\section{INTRODUCTION}

On October 17, 2018, Bill C-45 made non-medical cannabis possession, consumption, and sale legal for Canadian adults. While widespread cannabis use existed among Canadians prior to legalization, there has been concern over whether this policy change may increase health harms, including emergency department (ED) volumes and presentation patterns. ${ }^{1,2}$ Previous research has identified cannabis-related ED visit monitoring important, among many public health impact indicators for nonmedical cannabis liberalization. ${ }^{3}$ To minimize potential negative impacts of legalization on health services and public health, cannabis sales in Canada are strictly regulated both federally and provincially. For example, unlike the United States, advertising and promotions are forbidden in Canada, with cannabis requiring plain packaging and health warning labels. In Alberta, cannabis distribution and online sales are regulated by a provincial government agency, the Alberta Gaming, Liquor, and Cannabis Commission, which also oversees private retail outlet licensing. Alberta provides good context for researching the early impacts of legal cannabis on ED visits, as it has been the first Canadian province to implement and rapidly scale up legal cannabis sales, with 176 of Canada's 407 cannabis stores, and \$195 million dollars in sales. 4

Although cannabis is often associated with fewer acute harms when compared to substances like alcohol, tobacco, or opiates, short-term use is associated with paranoia, anxiety, suicidal ideation, psychosis, and impairment of memory, motor coordination, and judgement. ${ }^{5,6}$ Cannabis can also induce temporary tachycardia and cannabinoid hyperemesis syndrome, or onset of cyclical emesis in chronic users. ${ }^{7-9}$ Because cannabis can have differing effects on new and chronic users, it is necessary to examine co-diagnoses alterations in cannabis-involved patients to determine whether patient populations have changed. While Canada remains the first North American country to nationally legalize cannabis, several American states with legalized nonmedical cannabis have identified temporary changes in cannabis use associated with co-diagnoses patterns and cannabis-related ED presentations. ${ }^{10}$ Cannabis-related ED visits appear to be increasing across the United States, with the Drug Abuse Warning Network reporting a $49 \%$ increase. ${ }^{11}$ Legalization appears to have added a small, additional ED caseload, with Colorado reporting a $23 \%$ increase in cannabis-related $\mathrm{ED}$ visits on top of nationally reported visitation increase. ${ }^{12}$

To answer the overarching question of what impact cannabis legalization has had on EDs, we established two objectives. These were to 1) identify change in cannabis-related ED visit, telehealth, and poison control call volume; and 2) identify changes in cannabis-related co-diagnoses patterns in urban Alberta EDs pre- and post-legalization.

\section{METHODS}

\section{Study design and data collection}

This study involved analyses of administrative data preand post-legalization. Data were extracted from the National Ambulatory Care Reporting System (NACRS), 
the Alberta Poison and Drug Information Service, and HealthLink provincial databases. NACRS data for Alberta are among the highest-quality in Canada, as Alberta is among two provinces mandating full abstraction of all ED visits, ensuring no patients or their physician-made diagnoses are missed. ${ }^{13}$ The Alberta Poison and Drug Information Service is the provincial poison control service, available to both physicians and the public, and HealthLink is the public provincial telehealth service. Both provide telephone health advice to Albertans. ED data were obtained from October 1, 2013, to July 31, 2019; poison control data were obtained from May 1, 2016, to July 31, 2019; and HealthLink data were obtained from June 1, 2017, to July 31, 2019. Earlier data were unavailable from HealthLink or poison control. Data were split into annual quarters aligning with population estimates published by the Government of Alberta. Thus, the post-legalization period was defined as presentations from October 1, 2018, to July 31, 2019.

All data were collected from urban Alberta, defined as 14 Calgary and Edmonton area ED, inclusive of St. Albert and Sherwood Park, given their proximity to Edmonton. HealthLink and poison control data were collected province-wide, due to an inability to verify caller location. The study was approved by the University of Calgary research ethics board (REB19-0238).

\section{Population}

Eligible patients included those with a cannabis-related International Classification of Disease (ICD) code in primary or secondary diagnostic fields. The database did not allow differentiation between those reportedly using cannabinoids for medicinal use and those using cannabis for non-medicinal use. ICD was used to identify injuries and causes. Results were stratified by age, broken into 0-14 (child), 15-17 (adolescent), 18-24 (young adult), 25-44 (adult), 45-64 (older adult), and $65+$ (senior). ICD codes used included all mental and behavioural disorders due to cannabinoid use and cannabinoid poisonings. Hyperemesis was defined as vomiting paired with a cannabinoid code (no ICD code exists for cannabinoid hyperemesis syndrome; thus, it is necessary to combine codes). From patient data, we obtained ED visit date, age, sex, previous cannabis-related presentations, and hospital admission status. Co-ingestants were also identified using ICD codes. A full list of ICD codes used is available in Supplemental Table 1.
Cannabis-related calls to HealthLink and poison control were identified by identifying keywords "marijuana," "cannabis," or "cannabinoid" in the call or substance description. A co-diagnoses analysis was not conducted on calls due to ICD code absence.

\section{Data analysis and outcomes}

To determine whether significant changes occurred in overall volume, we conducted an interrupted time-series analysis via a segmented simple linear regression for volumes pre- and post-legalization within the ED, poison control, and HealthLink data sets. Monthly total call or visit volumes were analysed for all data sources. Due to the relatively short post-legalization period, we did not have enough data to reliably estimate a slope. Therefore, we estimated a common slope in the preand post-legalization periods and a level change at the time of legalization. A visual assessment did not reveal serial autocorrelation or seasonal trends in any time series. Secondly, we calculated incidence rate ratios (IRRs) to compare changes in presentation rate and diagnosis patterns for the entire urban Alberta population between the pre-legalization period and post-legalization period. Because interrupted time-series analysis accounts for pre-existing trends, we based conclusions about volume on the interrupted time-series rather than the IRR.

We also calculated relative-risk ratios (RRs) to compare changes in the proportion of cannabis-related ED visits that had different co-diagnoses pre- and postlegalization. The IRR allows for identification of changes in incident rate when compared against the entire Alberta population, whereas the RR allows for identification of changes among individuals who present to the ED. Both the IRR and RR were calculated using Wald confidence intervals (CIs) via the epi2by 2 command in $\mathrm{R}$ through the epiR package, with the population of urban Alberta and the number of cannabisrelated ED visits used as denominators, respectively.

Individuals missing data for a variable were omitted from the analysis of that variable, though only one case of missing data was identified. As the data were from an electronic database, it was difficult to identify whether data were missing elsewhere in the data set. All rates were adjusted to the 2019 third-quarter Alberta population to account for population growth. Ninetyfive percent CIs were calculated. Analysis occurred in $\mathrm{R}$ version 3.6.1. 


\section{Table 1. Demographics and clinical characteristics of cannabis-related ED visits}

\begin{tabular}{lcc}
\hline Variable & $n$ of Pre-legalization cohort $(\mathrm{N}=11,770)$ & $\mathrm{n}$ of Post-legalization cohort (N=2,962) \\
\hline Disposition & & $205(6.9)$ \\
Left without being seen & $640(5.4)$ & $41(1.4)$ \\
Left against medical advice & $171(1.5)$ & $115(3.9)$ \\
Transferred & $607(5.2)$ & $565(19.1)$ \\
Admitted to hospital & $2,553(21.7)$ & $1,996(67.4)$ \\
Discharged & $7,696(65.4)$ & $95(3.2)$ \\
Age groups & & $278(9.4)$ \\
Child (0-14) & $386(3.3)$ & $922(31.1)$ \\
Adolescent (15-17) & $1534(13.0)$ & $1267(42.8)$ \\
Young adults (18-24) & $3796(32.3)$ & $346(11.7)$ \\
Adult (25-44) & $4670(39.7)$ & $54(1.8)$ \\
Older adult (45-64) & $1288(10.9)$ & $1885(63.6)$ \\
Senior (65+) & $96(0.8)$ & $1113(37.6)$ \\
Sex & & $1028(34.7)$ \\
Male & $7679(65.2)$ & \\
Psychological co-diagnoses and co-ingestant totals & & \\
Psychological co-diagnoses* & $5259(44.8)$ & \\
Co-ingestant use* & $5296(45.0)$ & \\
\hline *Expanded upon in Supplemental Table 1. & &
\end{tabular}

\section{RESULTS}

\section{Characteristics of cannabis-related ED visits}

The sample, described in Table 1 , included 14,732 cannabis-related presentations, of which $64.9 \%$ were male. Mean age was $28.5(\mathrm{SD} \pm 12.2)$. We observed a mean of 45.1 patients presenting per week to the ED pre-legalization, and 68.9 patients presenting postlegalization. The most common co-ingestants were alcohol, cocaine, and other stimulants (Supplementary Table 1). The most common psychological diagnoses were for anxiety-related, personality and behavioural, affective mood, and non-mood psychotic disorders. Hyperemesis (12.2\%) and external injury (18.1\%) were also common. Cardiac and respiratory distress was also frequent, including heartbeat and blood pressure abnormalities, cough, and pain in the throat or chest (Supplementary Table 1 ).

\section{Volume analysis}

Cannabis-related visit volume increased post-legalization within urban EDs (IRR 1.45, 95\% CI; 1.39, 1.51) with the interrupted time-series indicating a change of 43.5 visits per month (95\% CI; 26.5, 60.4). Calls to poison control also increased (IRR 1.87, 95\% CI; 1.55, 2.24), with the interrupted time-series indicating a change of 4.02 calls per month (95\% CI; 0.11, 7.94). Changes for individual EDs varied between -11.5 and 12.6 visits per month, with an average of 3.1. HealthLink did not receive a significant increase in cannabis-related calls post-legalization.

\begin{tabular}{|c|c|c|c|}
\hline Data source & Data collection & $\begin{array}{l}\text { Absolute level change at legalization } \\
\text { from interrupted time series analysis, } \\
\text { visits/calls per month }(95 \% \mathrm{Cl})\end{array}$ & $\operatorname{IRR}(95 \% \mathrm{CI})$ \\
\hline Urban ED Presentations & October 1, 2013 to July 31, 2019 & $43.5(26.5,60.4)$ & $1.5(1.4,1.5)$ \\
\hline HealthLink* Calls & June 1, 2017 to July 31, 2019 & $-14.6(-57.5,28.4)$ & $2.2(2.1,2.3)$ \\
\hline PADIS** Calls & May 1, 2016 to July 31, 2019 & $4.0(0.1,7.9)$ & $1.9(1.6,2.4)$ \\
\hline
\end{tabular}




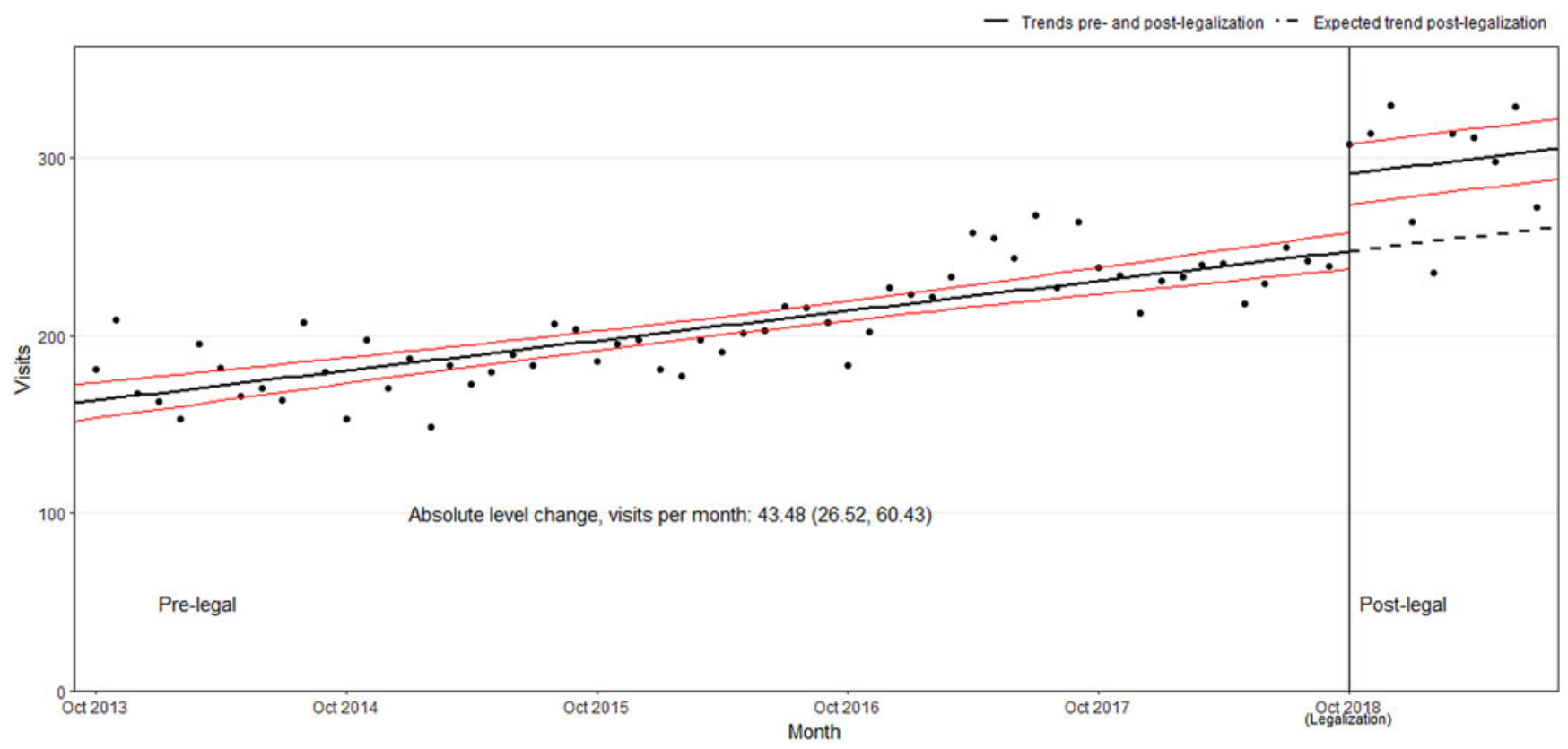

Figure 1. Urban emergency department cannabis-related visits over time.

Interrupted time-series results are within Table 2 and illustrated in Figure 1, Figure 2, and Supplemental Figure 3. As indicated in Table 2, the IRR for cannabis-related presentations was 1.45 (95\% CI; $1.39,1.51)$ or a $45 \%$ increase from 20.7 ED visits per 100,000 person-years to 30.1 . Of all cannabis-related visits, $15.1 \%$ were due to unintentional exposure. Unintentional exposures grew overall for all groups with the exception of seniors, and grew proportionally for all age groups with the exception of children and seniors.

\section{Presentation pattern and co-ingestant use analysis}

Ratios comparing the number and makeup of pre- and post-legalization cannabis presentations are described in Table 3. When observing the post-legalization period,

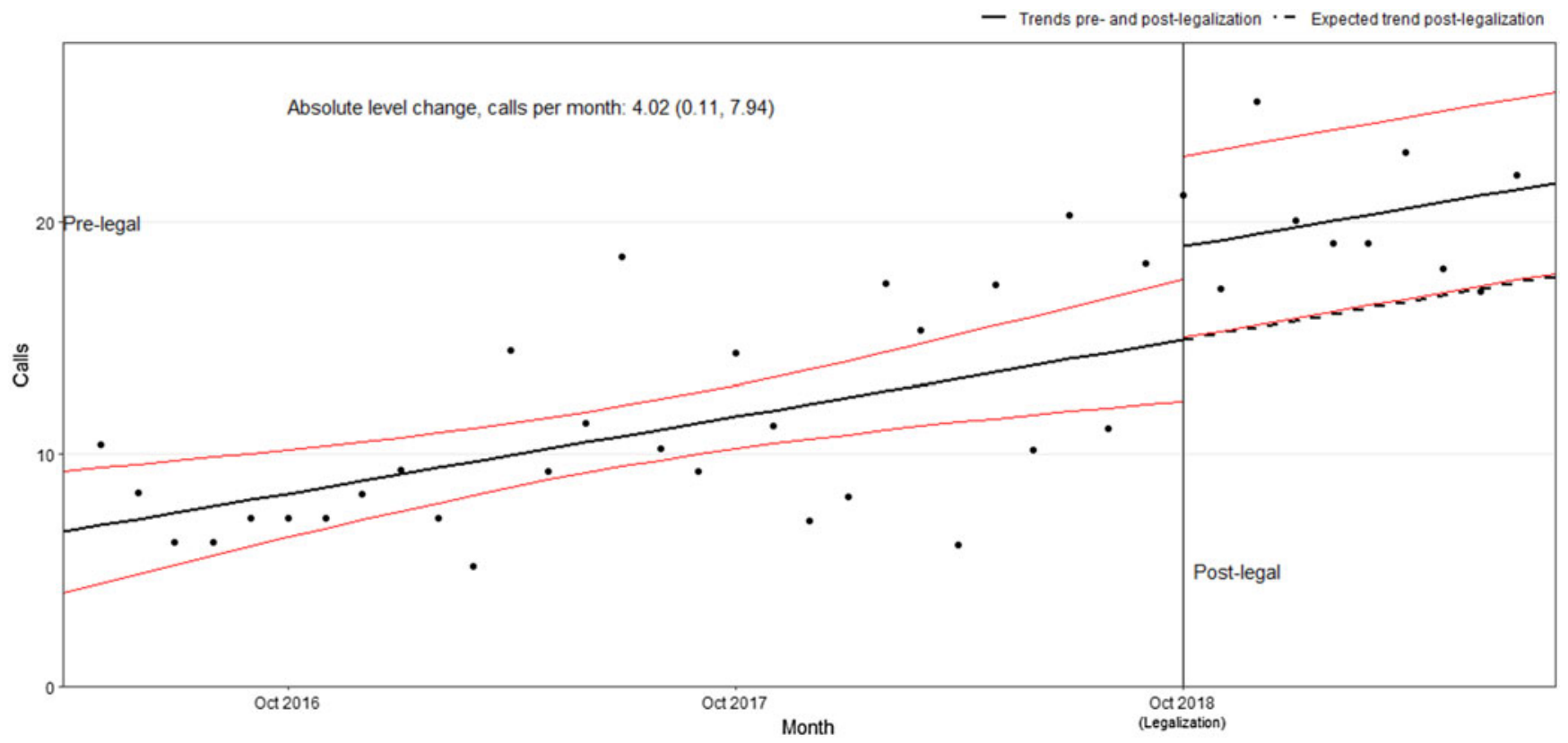

Figure 2. PADIS cannabis-related calls over time. 


\begin{tabular}{|c|c|c|}
\hline Variable & $\operatorname{IRR}(95 \% \mathrm{CI})$ & $\begin{array}{c}\text { RR among all } \\
\text { cannabis-related } \\
\text { ED visits }(95 \% \mathrm{Cl})\end{array}$ \\
\hline \multicolumn{3}{|l|}{ Age groups } \\
\hline Child (0-14) & $1.4(1.1,1.8)$ & $0.98(0.8,1.2)$ \\
\hline Adolescent (15-17) & $1.04(0.9,1.2)$ & $0.7(0.7,0.8)$ \\
\hline Young adults (18-24) & $1.4(1.3,1.5)$ & $0.97(0.9,1.04)$ \\
\hline Adult (25-44) & $1.6(1.5,1.7)$ & $1.1(1.00,1.1)$ \\
\hline Older adult (45-64) & $1.6(1.4,1.7)$ & $1.1(0.95,1.2)$ \\
\hline Senior $(65+)$ & $3.2(2.3,4.6)$ & $2.2(1.6,3.1)$ \\
\hline \multicolumn{3}{|l|}{ Disposition } \\
\hline Left without being seen & $1.8(1.6,2.2)$ & $1.3(1.1,1.5)$ \\
\hline Left against medical advice & $1.4(0.96,2.0)$ & $0.95(0.7,1.4)$ \\
\hline Transferred & $1.1(0.9,1.3)$ & $0.8(0.6,0.9)$ \\
\hline Admitted & $1.3(1.2,1.4)$ & $0.9(0.8,0.96)$ \\
\hline Discharged & $1.4(1.4,1.6)$ & $1.03(0.98,1.1)$ \\
\hline \multicolumn{3}{|l|}{ Psychological co-diagnoses } \\
\hline Psychological co-diagnoses & $1.2(1.1,1.3)$ & $0.8(0.8,0.9)$ \\
\hline Anxiety-related disorder & $1.2(1.1,1.4)$ & $0.9(0.8,0.95)$ \\
\hline $\begin{array}{l}\text { Non-mood psychotic } \\
\text { disorder }\end{array}$ & $1.2(1.01,1.3)$ & $0.8(0.7,0.9)$ \\
\hline Mood (affect) disorder & $1.01(0.9,1.1)$ & $0.7(0.6,0.8)$ \\
\hline $\begin{array}{l}\text { Adult personality and } \\
\text { behavioural disorder }\end{array}$ & $1.1(0.9,1.3)$ & $0.8(0.6,0.9)$ \\
\hline \multicolumn{3}{|l|}{ Physical co-diagnoses } \\
\hline Cardiac distress & $2.5(1.8,3.3)$ & $1.7(1.3,2.3)$ \\
\hline Respiratory distress & $1.7(1.3,2.2)$ & $1.1(0.9,1.5)$ \\
\hline $\begin{array}{l}\text { Signs and symptoms of } \\
\text { mental disorder }\end{array}$ & $1.9(1.5,2.5)$ & $1.3(1.01,1.7)$ \\
\hline Hyperemesis & $1.8(1.6,2.0)$ & $1.2(1.1,1.4)$ \\
\hline \multicolumn{3}{|c|}{ External injury and unintentional ingestion } \\
\hline External accidental injury & $2.0(1.8,2.2)$ & $1.4(1.3,1.5)$ \\
\hline Child (0-14) & $1.7(1.2,2.5)$ & $1.2(0.8,1.8)$ \\
\hline Adolescent (15-17) & $1.5(1.2,1.9)$ & $1.4(1.1,1.9)$ \\
\hline Young adults (18-24) & $2.1(1.8,2.5)$ & $1.5(1.3,1.8)$ \\
\hline Adult (25-44) & $2.0(1.8,2.4)$ & $1.3(1.1,1.5)$ \\
\hline Older adult (45-64) & $2.4(1.9,3.0)$ & $1.5(1.2,1.9)$ \\
\hline Senior $(65+)$ & $2.0(0.9,4.0)$ & $0.6,(0.3,1.2)$ \\
\hline Unintentional ingestion & $2.1(2.0,2.4)$ & $1.5(1.3,1.6)$ \\
\hline Child (0-14) & $1.9(1.3,2.8)$ & $1.3(0.9,2.0)$ \\
\hline Adolescent (15-17) & $1.7(1.3,2.2)$ & $1.7(1.3,2.1)$ \\
\hline Young adults (18-24) & $2.0(1.7,2.4)$ & $1.3(1.2,1.7)$ \\
\hline Adult (25-44) & $2.3(2.0,2.7)$ & $1.5(1.3,1.7)$ \\
\hline Older adult (45-64) & $2.7(2.1,3.5)$ & $1.7(1.3,2.2)$ \\
\hline Senior $(65+)$ & $2.1(0.9,4.3)$ & $0.7(0.3,1.3)$ \\
\hline \multicolumn{3}{|l|}{ Co-ingestants* } \\
\hline Co-ingestant use & $1.1(1.04,1.2)$ & $0.8(0.7,0.8)$ \\
\hline Alcohol & $1.1(1.01,1.2)$ & $0.8(0.7,0.8)$ \\
\hline Opiates & $1.01(0.8,1.3)$ & $0.7(0.6,0.9)$ \\
\hline Sedatives & $1.4(1.1,1.7)$ & $\begin{array}{l}0.9(0.7,1.2) \\
\quad(\text { Continued })\end{array}$ \\
\hline
\end{tabular}

\begin{tabular}{|lrc|}
\hline Table 3. Continued. & $\begin{array}{c}\text { RR among all } \\
\text { cannabis-related }\end{array}$ \\
\hline Variable & IRR $(95 \% \mathrm{CI})$ & ED visits $(95 \% \mathrm{CI})$ \\
\hline Cocaine & $0.8(0.7,1.0)$ & $0.6(0.5,0.7)$ \\
Stimulant & $1.2(1.1,1.4)$ & $0.8(0.7,0.95)$ \\
Hallucinogen & $1.1(0.7,1.6)$ & $0.8(0.5,1.1)$ \\
Other & $0.98(0.9,1.1)$ & $0.7(0.6,0.8)$ \\
\hline *Inhalants and nicotine excluded due to low sample size. & \\
\hline
\end{tabular}

individuals presenting with cognitive disorder symptoms (32\%), cardiac distress (71\%), and hyperemesis (23\%) increased relative to overall cannabis-related presentations. The increase in cardiac distress-related presentations was led by younger adults (RR 2.7, 95\% CI; 1.7, 4.2) and adults (RR 2.4, 95\% CI; 1.5, 3.8). An increase was also observed in external injuries associated with cannabis (39\%). We found decreases in several psychiatric co-diagnoses, including non-mood psychotic (-21\%), mood-related $(-30 \%)$, personality and adult behavioural $(-25 \%)$, and anxiety-related disorders (-14\%). Patient disposition remained similar throughout the study period, though we noted an increase in the proportion of patients who left the ED prior to treatment (28\%), and a decrease in individuals admitted to hospital proportional to the cannabis-related presentation total (-12\%).

With respect to co-ingestants, a decrease in the proportion of individuals reporting co-ingestant consumption overall was found $(-23 \%)$ with statistical significance identified for cocaine (-42\%), alcohol (-24\%), stimulants $(-16 \%)$, opiates $(-31 \%)$, and unclassified drugs $(-32 \%)$ (see Table 3$)$.

With respect to age group differences, we identified increased visitation among all age groups, though increased visitation was particularly pronounced in individuals over age 45 (see Table 3). Incident rates climbed overall, as expected, given the $45 \%$ increase in patient volume.

\section{DISCUSSION}

This is the first study reporting on ED impacts of national cannabis legalization, using a national highquality standardized database. Our research in a province with rapidly scaled up cannabis sales may help inform future global policies surrounding cannabis legalization, and may help advise the global emergency medicine community on the impacts of cannabis legalization. 


\section{Interpretation of findings}

\section{Volume analysis of ED visits and calls to telehealth services}

Interrupted time-series analyses suggest that, overall, cannabis legalization led to a statistically significant increase in ED visits and poison control calls. The increase in $\mathrm{ED}$ visits and poison control calls is similar to changes observed in the United States. ${ }^{12-16} \mathrm{We}$ hypothesize increased visitation steams from increased cannabis use following legalization and increased social acceptability, leading to more individuals seeking help for cannabis-related health issues or reporting cannabis use. Though it is possible existing cannabis users are now consuming more cannabis than previously, we believe the increase in cannabis-related visits is due to new users. The difference in individuals who have visited the ED for a cannabis-related event in the past 5 years was less than $1 \%$ when comparing the pre-legalization and post-legalization periods.

\section{Cannabis-related harm patterns and co-ingestant use analysis}

The IRR analysis indicated an increase in the majority of diagnosis categories, likely due to increased overall cannabis-related visits mentioned previously. However, the RRs tell a very different story, with fewer comorbidities identified post-legalization per cannabis-related visit. Per cannabis visit, decreases were observed in all psychological co-diagnoses and in the majority of co-ingestant categories. We hypothesize decreasing co-ingestant and psychological co-diagnoses presentation to stem from a changing patient population involving new users purchasing cannabis due to availability and legality. New users may not be aware of cannabis' physical effects, increasing the visit proportion for physical co-diagnoses and decreasing the proportion for psychological co-diagnoses. This trend may also be responsible for fewer admittances and more discharges post-legalization. We attribute the lower proportion of individuals reporting co-ingestant use to public health campaigns highlighting poly-substance use dangers and the poor availability of other co-ingestants.

Additionally, we note increases in cannabis-related physical co-diagnoses, including hyperemesis and cardiac distress, in addition to increases in unintentional ingestion and accidental external injury. The increase in cardiac distress symptoms appears to be associated with the increase in new users unfamiliar with the effects of cannabis, particularly among younger adults. Similarly, the increase in unintentional ingestions is led by adults and older adults, though the incidence rate of children and adolescent presentations has also increased. We hypothesize these trends to stem from increased usage among older adults, possibly for self-medication and because of the presence of cannabis belonging to a younger member of the household.

\section{Contextualizing results}

Overall, cannabis-related harm remains a very small subset of urban ED visits, with approximately 3 visits per 1,000 attributable to cannabis. Though this figure indicates ED visits related to cannabis may be greater in comparison to some prescription drugs, the substance is associated with fewer ED visits in comparison with other common substances like alcohol and opiates. ${ }^{14,15}$

\section{LIMITATIONS}

Inherent to administrative data use is the possibility of miscoded patients. Additionally, it is likely that cannabis legalization has altered stigma and patient fears of legal repercussions. Though cannabis use is likely underreported within administrative data and during ED visitation, particularly pre-legalization, the National Ambulatory Care Reporting System remains the only nationally standardized ED database reflecting an internationally recognized coding scheme for ED visitation. ${ }^{16}$ Conducting more invasive testing, particularly on past patients, is simply not tenable. Additionally, it is not known how often providers contact poison control for cannabis-related inquiries. Our methodology remains similar to other studies examining ED cannabis impacts. ${ }^{17}$

\section{Clinical implications}

The study has identified significant increase in cannabisrelated ED visit volume subsequent to cannabis legalization. However, when considering actual clinical implications for individual sites, the daily impact of cannabis-legalization remains low, with the greatest increase in mean monthly presentation rate for an individual ED at 12.6 visits. Clinicians should remain vigilant of increasing unintentional exposures, particularly among older adults, given potentially more serious harms. Clinicians should also remain vigilant of 
cannabinoid hyperemesis syndrome, with increasing prevalence within the general population and as a proportion of cannabis-related ED presentations.

\section{Research implications}

Given the rapidly changing nature of Canadian cannabis legislation, cannabis-use levels will continue to change. It is important that similar studies and monitoring continue across the country over an extended period. Lastly, our results have indicated an increase in accidental cannabis ingestion in those ages 15-64. Future research and policy may wish to target those populations with educational interventions to reduce harm, like accidental ingestion.

\section{CONCLUSION}

Overall, results show that cannabis legalization is associated with an increase in cannabis-related ED presentations, with a marked increase in older adults. However, the overall impact of early stage legalization on ED operation remains low, with limited volume increase for individual sites. Results also indicate that most co-diagnoses patterns have remained stable or declined, as is the case for psychological co-diagnoses. Notably, increases in some physical manifestations were observed. Nonetheless, rising accidental ingestions remain concerning and should be targeted for prevention.

Supplementary material: The supplemental material for this article can be found at https://doi.org/10.1017/cem.2020.384.

Acknowledgements: We would like to thank PADIS and HealthLink data analysts for their assistance in sourcing data from their respective organizations. We would also like to thank analysts with the Alberta Health Services Strategy for Patient Oriented Research data platform for their assistance in retrospective data collection.

Financial support: MEMY was supported through an Alberta Health Services Emergency Strategic Clinical Network summer studentship grant for this research.

Competing interests: None declared.

\section{REFERENCES}

1. Fischer B, Rehm J, Crépault J-F. Realistically furthering the goals of public health by cannabis legalization with strict regulation: response to Kalant. Int 7 Drug Policy 2016;34:11-6.
2. Statistics Canada. Canadian Tobacco, Alcohol and Drugs Survey (CTADS): summary of results for 2017. Ottawa: Statistics Canada; 2019. Available at: https://www.canada.ca/ en/health-canada/services/canadian-tobacco-alcohol-drugssurvey/2017-summary.html (accessed December 14, 2019).

3. Lake S, Kerr T, Werb D, et al. Guidelines for public health and safety metrics to evaluate the potential harms and benefits of cannabis regulation in Canada. Drug Alcohol Rev 2019;38(6):606-21.

4. Statistics Canada. The retail cannabis market in Canada: a portrait of the first year. Ottawa: Statistics Canada; 2019. Available at: https://www150.statcan.gc.ca/n1/pub/11-621m/11-621-m2019005-eng.htm (accessed March 25, 2020).

5. Volkow ND, Baler RD, Compton WM, Weiss SRB. Adverse health effects of marijuana use. $N$ Engl 7 Med 2014;370 (23):2219-27.

6. Karila L, Roux P, Rolland B, et al. Acute and long-term effects of cannabis use: a review. Curr Pharm Des 2014;20 (25):4112-8.

7. Galli JA, Sawaya RA, Friedenberg FK. Cannabinoid hyperemesis syndrome. Curr Drug Abuse Rev 2011;4(4):241-9.

8. Goyal H, Awad HH, Ghali JK. Role of cannabis in cardiovascular disorders. 7 Thorac Dis 2017;9(7):2079-92.

9. Hasin DS, Saha TD, Kerridge BT, et al. Prevalence of marijuana use disorders in the United States between 2001-2002 and 2012-2013. 7AMA Psychiatry 2015;72(12): $1235-42$.

10. Hall KE, Monte AA, Chang T, et al. Mental health-related emergency department visits associated with cannabis in Colorado. Acad Emerg Med 2018;25(5):526-37.

11. Zhu H, Wu LT. Trends and correlates of cannabis-involved emergency department visits: 2004 to 2011. F Addict Med 2016;10(6):429-36.

12. Kim HS, Monte AA. Colorado cannabis legalization and its effect on emergency care. Ann Emerg Med 2016;68(1):71-5.

13. CIHI. Data Quality Documentation National Ambulatory Care Reporting System current-year information 20182019. Ottawa: CIHI; 2019. Available at: https://www.cihi. $\mathrm{ca} /$ sites/default/files/document/current-year-informationnacrs-2018-2019-en-web.pdf (accessed December 15, 2019).

14. O'Connor S, Grywacheski V, Louie K. At-a-glance - hospitalizations and emergency department visits due to opioid poisoning in Canada. Health Promot Chronic Dis Prev Can 2018;38(6):244-7.

15. Myran DT, Chen JT, Giesbrecht N, Rees VW. The association between alcohol access and alcohol-attributable emergency department visits in Ontario, Canada. Addiction 2019;114(7):1183-91.

16. CIHI. Data Quality Documentation National Ambulatory Care Reporting System multi-year information. Ottawa: CIHI; 2019. Available at: https://www.cihi.ca/sites/default/ files/document/nacrs_multi-year_info_en.pdf (accessed March 25, 2020).

17. Public Health Ontario. Indicators for monitoring cannabisrelated health outcomes. Toronto: Public Health Ontario; 2019. Available at: https://www.publichealthontario.ca/-/ media/documents/rapid-review-cannabis-indicators.pdf?la= en (accessed March 25, 2020). 